\title{
Ethnic Fragmentation and Police Spending: Social Identity and a Public Good*
}

\author{
Olugbenga Ajilore ${ }^{\dagger}$ and John Smith ${ }^{\ddagger}$
}

October 9, 2007

\begin{abstract}
We present evidence that more ethnically fragmented communities spend, all else equal, more on police services than less fragmented communities. We introduce a model of spending on police services which we use to interpret the data. In this model, we assume that the decision to commit a crime is a rational consideration of the costs and benefits and that spending on police services reduces the attractiveness of committing a crime. We also assume that being a victim of crime affects a loss in utility. However this victimization cost, if victim and perpetrator are a different ethnicity, is greater than or equal to that if the perpetrator is the same ethnicity. A consequence of the model is that a higher level of spending on police services is associated with more ethnically fragmented communities only when agents suffer this differential cost of victimization. These results contribute to our understanding of the stylized fact that spending on police services is increasing at a time in which crime rates are falling. Further, our results provide empirical support for the contention that people have a larger cost of victimization when the perpetrator is a different ethnicity.
\end{abstract}

\footnotetext{
${ }^{*}$ The authors would like to thank W. David Allen, Jack Worrall and participants of the 2007 Western Economics Association Conference for helpful comments.

${ }^{\dagger}$ University of Toledo; Email: gajilor@UTNet.UToledo.Edu.

${ }^{\ddagger}$ Rutgers University-Camden; Email: smithj@camden.rutgers.edu; Phone: (856) 225-6319; Website: http://crab.rutgers.edu/ ${ }^{\sim}$ smithj/.
} 


\section{Introduction}

Prior to the 1990's, the United States witnessed a surge in crime rates. Somewhat predictably, this increase was accompanied by an increase in local expenditures on police protection and corrections. However, crime rates did not continue to increase (as some predicted) and actually began to decrease during the late 1990's. Although some found it surprising that the crime rate decreased, it should be even more surprising that spending on police and corrections continued to rise. Figure 1 below demonstrates that during the 1990's, roughly speaking, spending on police services increased, while violent crime decreased.

Figure 1 Spending on Police Services and Crime Rates 1989-2000

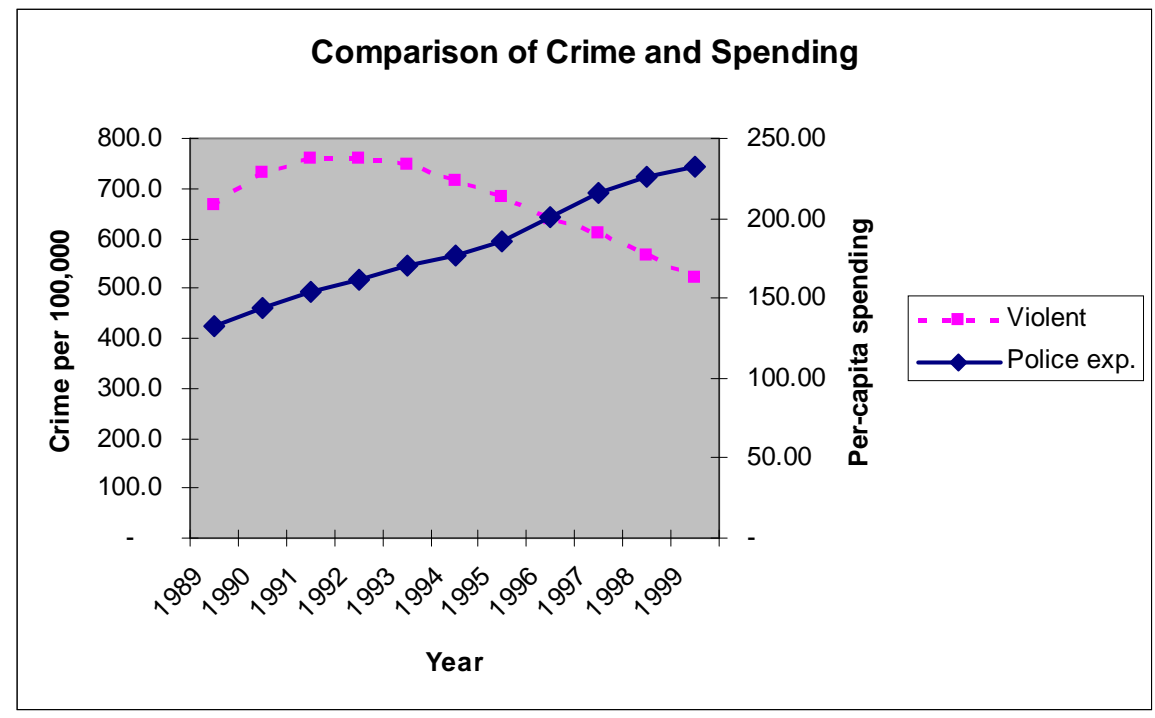

It seems plausible to conclude that concern over crime increased despite that the actual crime rates decreased. Why would there be increased concerns about crime? We assert that individuals exhibit an increased fear of crime when their community becomes more ethnically fragmented. ${ }^{2}$ Specifically, we contend that the utility loss from crime victimization is differentially larger when the perpetrator is a different ethnicity than the victim. We argue that this differential victimization cost leads to a positive relationship between ethnic fragmentation and spending on police services.

In this paper, we present evidence that, all things equal, ethnic fragmentation is positively related to spending on police services in United States counties. Note that we use the standard definition of ethnic fragmentation: the probability that two randomly selected people in a community are of different ethnicities. ${ }^{3}$

\footnotetext{
${ }^{1}$ Bureau of Justice Statistics. Spending is listed in Real 2000 dollars.

${ }^{2}$ There is a large literature in political science and sociology about the media's role in shaping public opinion about the true level of crime and the perceived criminality about certain groups. We do not address this in the paper.

${ }^{3}$ See for instance Alesina, Baqir, and Easterly (1999) or Hero and Tolbert (1996).
} 
To aid in the interpretation of this data, we present a model where we make the following assumptions regarding crime. We assume that the decision to commit a crime is a rational consideration of the costs and benefits. We assume that spending on police increases the likelihood of apprehending a person who commits a crime. Finally, we assume that every person incurs a cost from being a victim of crime. However, this victimization cost, if victim and perpetrator are of the same ethnicity, is less than or equal to that if the perpetrator is a different ethnicity. We interpret the expectation of the future cost associated with crime victimization to be the fear of crime. Our model implies that if the interethnic victimization cost is larger than the intraethnic cost then fear of crime is increasing in ethnic fragmentation. If the interethnic victimization cost is identical to intraethnic cost then fear of crime is not increasing in ethnic fragmentation.

In our model, agents decide on a political outcome related to police services, then are matched with another agent where both decide to commit a crime or not. Spending on police services reduces the fear of crime through reducing the expected victimization costs. We use standard median voter arguments to arrive at a particular political outcome. An implication of our model is that if a non-criminal from the majority group ${ }^{4}$ is the pivotal voter and if there is a differential victimization cost then an increase in ethnic fragmentation of a community will lead to a larger amount of spending on police. If there is no differential victimization cost then ethnic fragmentation is unrelated to police spending.

We use this model to interpret the data involving spending on police services and ethnic composition. Specifically, we estimate a panel instrumental variables regression of data from United States counties. The results suggest that when accounting for standard factors, ethnic fragmentation is positively related to police spending.

We interpret this empirical finding as supporting our contention that people have a stronger disutility of crime when the perpetrator is a different ethnicity. Moreover, our results help illuminate the puzzle that crime rates are decreasing over a period in which spending on police is increasing.

\section{$1.1 \quad$ Related Literature}

Moore and Shepherd (2006) and Moore (2006) measure the "intangible" costs of crime such as the emotional distress caused by the fear of crime. While our model does not contain emotional distress per se, we interpret our model as examining the trade-off between avoiding fear crime and spending on police services to reduce this fear.

Although it is intuitive that people can have preferences over material outcomes based on the social group of the recipients, it is only recently that a literature has examined the economic nature of these interdependent preferences. For instance, Luttmer (2001) shows

\footnotetext{
${ }^{4}$ As is standard, throughout this paper we refer to a majority as having a population share greater than 0.5 .
} 
that preferences regarding welfare spending is increasing in the share of recipients in their own ethnic group. Alesina, Baqir and Easterly (1999) find that ethnic fragmentation is negatively related to the provision of productive public goods. Poterba (1997) finds that educational spending is negatively related to the difference between the ethnicities of the elderly population and the school-age population. This literature postulates that people have interdependent preferences and that these preferences drive the empirical results.

Since ethnic identity can affect preferences for spending on items such as welfare, the question becomes, "Can ethnic identity affect the fear of crime?" Evidence from sociology suggests an affirmative answer. For instance, Bursik and Grasmick (1993) present a heterogeneity model in which they argue that increases in racial and ethnic heterogeneity serve as signals that crime could potentially increase based on stereotypes and an unfamiliarity with other ethnic groups.

Authors have sought to test this heterogeneity model through survey data. Quillian and Pager (2001) examine the relationship between the racial composition of the community and perceptions of crime in their community. The authors find that, while controlling for measures of crime, community perceptions of crime are increasing in the percentage of young black men. Chiricos, McEntire, and Gertz (2001) explore the relationship between the perceived crime rate and the perceived level of blacks and Hispanics in the community. These authors find that higher perceived level of minorities is positively related to the perceived level of crime. Finally, Barkan and Cohn (2005) find that a significant amount of the preferences for spending on the reduction of crime can be attributed to prejudiced beliefs regarding African-Americans.

The conclusion which we take from this sociology literature is that as a community becomes more ethnically fragmented, fear of crime increases. Specifically, we believe this supports the contention that the cost of crime victimization is increasing in expectation that the perpetrator is a different ethnicity.

Starting with Becker (1968) it has been standard in economics to model the decision to commit a crime as a rational reflection on the costs and benefits. Although subsequently there have been many papers modeling crime, the closest to our approach is Fender (1999). ${ }^{5}$ As we do in this paper, Fender assumes that agents derive heterogenous benefits from committing a crime and that if a person does commit a crime, a cost is imposed on the victim. Further, Fender examines the aggregate implications of the decision to commit a crime in a population setting. ${ }^{6}$ We share with Fender the feature that the crime rates and the probability of apprehension are jointly determined. However, we focus on somewhat different issues. While Fender is primarily concerned with the interaction of crime rates and probability of apprehension, we are primarily focused on the interaction between ethnic fragmentation and police spending (which we assume is positively related to the probability of apprehension).

\footnotetext{
${ }^{5}$ Also see Volume 45, Issue 3 of the International Economic Review for recent advances in modeling criminal behavior.

${ }^{6}$ Perrson and Claes-Henric (2006) takes a similar approach, with the exception that criminals have a higher degree of time impatience than do non-criminals.
} 
Although economics papers make similar assumptions regarding preferences to minimize the number of criminal incidents, we note that the empirical evidence supports these assumptions. For instance, Machin and Marie (2005) find that spending on police reduces the incidence of crime. We view this finding as supporting the results of our model. It should be noted, however, that we did not assume this relationship, but rather the relationship naturally emerges from our model.

Our approach to comparing the fragmentation of different communities also deserves some comment. Fragmentation is a mapping from an arbitrary number of group sizes into the unit interval. However, the interpretation of this numerical value is not unproblematic. By this we mean that, when comparing two communities, the numerical value of fragmentation might not accurately represent the degree of heterogeneity. This can occur, if for instance, one community has many more groups than another. Esteban and Ray (1994) realize that an analogous problem can occur when comparing the degree of polarization of different communities. Similar to these authors we employ a strategy of restricting the ways in which we compare the fragmentation of communities. In our case, we will only compare fragmentation between two communities by means which we shortly explain in detail.

Finally, note that we are not the first to observe a positive relationship between spending on police services and ethnic fragmentation. Alesina, Baqir and Easterly (1999) find that ethnic fragmentation is positively related to the share of county spending on police. However, in contrast to these authors, we consider the crime rates and ethnic group shares in their influence of police spending.

\section{Model}

We suppose there is a continuum population of individuals $i \in[0,1]$. Each individual $i$ is a member of exactly one ethnic group. The ethnicity of agent $i$ has population share $q_{i}$. For each of these ethnicities $j \in\{1,2, \ldots, n\}=G$ we write the largest as $q_{1}$ descending to the smallest, $q_{n}$. We denote the profile $q_{1}, q_{2}, \ldots, q_{n}$ as $q$. Communities will only differ in their allocation of population into ethnicities, therefore we can refer to a community as $q$.

As mentioned in the introduction, the standard definition of fragmentation is the probability that two randomly chosen members of a community are different ethnicities. Therefore, we define the fragmentation $(\phi)$ of community $q$ as:

$$
\begin{aligned}
\phi(q) & =\sum_{j \in G}\left(q_{j}\right)\left(1-q_{j}\right) \\
& =1-\sum_{j \in G}\left(q_{j}\right)^{2}
\end{aligned}
$$

We assume that each player has preferences over money and incidents involving crime. We make standard assumptions regarding utility of money. In particular, we assume that 
$u($.$) is differentiable, increasing, and concave. Every agent is endowed with identical wealth$ $w$ and makes a contribution to police spending $e_{i}$. The agent also incurs a separable cost of future criminal victimization, which interpret as the cost of fear of crime and denote as $E_{i}[X]$. Therefore, utility can be written as:

$$
U_{i}(e)=u\left(w-e_{i}\right)+E_{i}[X]
$$

As the contributions to spending on police services are determined by a political outcome, we assume that the actual expenditures are identical across members of society $\left(e_{i}=e_{j}\right.$ for every $i, j \in N)$. We denote this actual contribution as $\bar{e}$.

The function $f$ is a mapping from spending on police services into the probability that a person who commits a crime will be apprehended $(f:[0, w] \rightarrow[0,1])$. We make the assumptions that $f(0)=0$ and that $f(w)=1$. These assumptions mean that if there is no spending on police services then the probability that a perpetrator will be apprehended is zero. Also if the community spends its entire wealth on police services then the probability that a perpetrator will be apprehended is one. We assume that $f($.$) is differentiable, increasing and$ concave.

In the first stage of the game, players decide on an amount of spending on police services. Consistent with the median voter literature we assume, although we do not explicitly model, that there are two candidates who are purely motivated by holding office. Each candidate offers a platform, which proposes the amount of spending on police services. As is well known, both candidates select a platform equal to the optimal amount of the median voter.

We also make the following assumption so that the optimal amount of spending on police services of the non-criminal majority is always between 0 and $w$ :

$$
\frac{u^{\prime}(0)}{f^{\prime}(w)}>\frac{1}{\theta}\left(1+\left(1-q_{1}\right) \alpha\right)>\frac{u^{\prime}(w)}{f^{\prime}(0)}
$$

If expression (2) did not hold, then a non-criminal member of the majority group might have a corner solution regarding their optimal spending on police services.

In the second period of the game, each agent is matched with another agent and both simultaneously decide to commit a crime or not. Every person derives a benefit from committing a crime. We interpret $x$ as the additional utility from committing a crime and not being caught. The value of $x$ for each person is distributed uniformly on $[0, \theta]$ where $\theta>1$. Given that a person commits a crime, they will be caught with probability $f(\bar{e})=c$. We write the payoff from being caught as $x-1$. Therefore we write the expectation of committing a crime as:

$$
\begin{gathered}
c(x-1)+(1-c) x \\
=x-c
\end{gathered}
$$


In the event that the opponent does not commit a crime, not committing a crime yields a payoff of 0 . In the event that the opponent does not commit a crime, committing a crime yields a payoff of $x-c$.

The second period match will either be described as an ingroup match or an outgroup match. If players $i$ and $j$ are matched and are both members of the same ethnic group, then we will say that it is an ingroup match. If players $i$ and $j$ are matched and are not both members of the same ethnic group then we will say that it is an outgroup match.

We define $-z$ as the disutility arising from being a victim of crime based on the ethnicity of the perpetrator. Specifically, $z$ is:

$$
z=\left\{\begin{array}{c}
\alpha \geq 0 \text { if outgroup match } \\
0 \text { if ingroup match }
\end{array}\right.
$$

In the event that the opponent does commit a crime, committing a crime yields a payoff of $x-c-z$. In the event that the opponent does commit a crime, not committing a crime yields a payoff of $-z$. The value of $z$ is given the following interpretation: crime is possibly more costly to the victim when the perpetrator is a different ethnicity. Note that the value of $z$ does not affect the attractiveness of committing a crime as only the values of $x$ and $c$ influence that decision The value of $z$ only renders the status of being a victim of crime less desirable when the perpetrator is a different ethnicity.

Therefore we write the above information in the following strategic form:

\begin{tabular}{|l|l|l|}
\hline & Crime & No Crime \\
\hline Crime & $x-c-z, y-c-z$ & $x-c,-z$ \\
\hline No Crime & $-z, y-c$ & 0,0 \\
\hline
\end{tabular}

In the matrix (3), the variables $x$ and $y$ are the additional utilities, for players 1 and 2 respectively, from committing a crime and not being caught. These values are distributed according to the uniform distribution on $[0, \theta]$.

To review the timing: in the first stage, the players determine the spending on police services. The median voter wins and every member of the game contributes $\bar{e}$. In the second stage, players are randomly matched and are possibly a victim of crime.

We now discuss some of the assumptions of the model. Perhaps the most surprising assumption is that the identity of victim does not affect the payoffs to the criminal. We make this assumption, in part, because we do not need to assume otherwise for the results to hold. Specifically, the positive relationship between fragmentation and police spending exists without making such an assumption. Further, we have nothing to say on the matter as our data does not allow us to compare ingroup and outgroup crime rates. ${ }^{7}$ Finally, a more

\footnotetext{
${ }^{7}$ Although we seek such data, for use in future work.
} 
complicated model would add little to our interpretation of the data. Criminals might prefer an outgroup victim. Criminals might also prefer a victim conveniently located nearby and these are likely to be members of their ingroup. We could have produced a more realistic model where criminals care about the ethnicity of the victim along with a search model, however these specific assumptions would drive our results. Additionally, these complications would add little to the interpretation of our data.

We also make the following technical assumptions for convenience. We assume that the population is composed of the unit interval. This assumption removes the nondivisablilty complications which arise in a finite population. We also assume that each player is matched with only one player. This implies that each criminal can only commit one crime. We could have allowed for a more complicated model in which one person can commit several crimes, however this would not affect the main results of the paper and would not aid in the interpretation of the data. Finally, note that everything which follows could be presented as a game in which we seek Perfect Bayesian Equilibria. However, the results which follow would be one of many equilibria and these complications would only obscure the main point of the paper.

\section{Results}

We now demonstrate the main implications of the model. If agents have a differential disutility of crime victimization and if the majority non-criminal is a pivotal voter, then ethnic fragmentation is positively associated with per capita spending on police services. Additionally, if agents do not have such a differential disutility, then ethnic fragmentation will not be related to spending on police services.

Before we begin, it should be noted why we take the following approach to comparing the fragmentation of two communities. The mapping from a general community profile $q=$ $\left(q_{1}, \ldots, q_{n}\right)$ into fragmentation is given by expression (1). However, the value of fragmentation only imperfectly conveys the characteristics of the society. The following example illustrates the confusion which can arise.

Example 1 Consider two communities. The first has the following composition

$$
q=(0.55,0.45)
$$

and the second has the following composition

$$
q^{\prime}=(0.8,0.1,0.01,0.01,0.01,0.01,0.01,0.01,0.01,0.01,0.01,0.01,0.01)
$$

A calculation of the values of fragmentation reveal that $\phi(q)=0.495$ and $\phi\left(q^{\prime}\right)=0.349$.

In Example 1, we view community $q^{\prime}$ as more heterogenous than community $q$. However, 
the example demonstrates that $\phi(q)>\phi\left(q^{\prime}\right)$. It is for this reason that we restrict attention to the following two ways in which we compare fragmentation between communities.

1. Both communities have $N$ groups and that $N-2$ of them have identical size. The community with the largest of the groups of unequal size will have a lower degree of fragmentation. (Lemma 1)

2. The first community has $N-1$ groups and the second has $N$ groups. Both communities have $N-2$ identically sized groups. The first community will have a smaller degree of fragmentation than the latter. (Lemma 2)

We state these comparisons formally in the following two lemmas. In the first comparison, we require that both groups the same number of groups and that all but two have the same size. In this case, the community with the smaller of the large group (and the larger of the small group) will have a larger measure of fragmentation.

Lemma 1 Consider communities $q$ and $q^{\prime}$ which each have $N \geq 2$ groups and that $N-2$ groups in each have equal size. For the remaining two groups $q_{a}=q_{\alpha}^{\prime}-A$ and $q_{b}=q_{\beta}^{\prime}+A$. If $A>0$ and $q_{\beta}^{\prime}>q_{\alpha}^{\prime}$ then $\phi(q)<\phi\left(q^{\prime}\right)$.

Proof. See Appendix.

One can visualize Lemma 1 by considering a community and shift some mass from a large group to a small group. This new community (made from shifting mass in the old community) will have a larger degree of fragmentation than the old community. Suppose that we compare communities $q=(0.6,0.2,0.1,0.1)$ and $q^{\prime}=(0.6,0.15,0.15,0.1) . \quad$ As $q_{2}>q_{2}^{\prime}$ and $q_{3}<q_{3}^{\prime}$, Lemma 1 implies that $\phi(q)<\phi\left(q^{\prime}\right)$.

The following Lemma formalizes point 2. If a community has one less group than a second community, and that all but one group in the first is the same size as all but two in the second, then we say that the second community has a higher degree of fragmentation.

Lemma 2 Consider community $q$ with $N-1$ groups and and $q^{\prime}$ with $N$ groups. If there are $N-2$ identical groups in both $q$ and $q^{\prime}$ and that group $q_{k}$ in community $q$ is identical to the sum of two groups $q_{\kappa}^{\prime}$ and $q_{\delta}^{\prime}$ in $q^{\prime}\left(q_{k}=q_{\kappa}^{\prime}+q_{\delta}^{\prime}\right)$ then $\phi(q)<\phi\left(q^{\prime}\right)$.

Proof. See Appendix.

One can visualize Lemma 2 by considering the case where one group in a community is split into two groups. This new community will have a larger degree of fragmentation then the old community. Suppose that we compare communities $q=(0.6,0.3,0.1)$ and $q^{\prime}=(0.6,0.17,0.13,0.1)$. As $q_{2}=q_{2}^{\prime}+q_{3}^{\prime}$, Lemma 2 implies that $\phi(q)<\phi\left(q^{\prime}\right)$.

As we have defined the two ways in which we compare fragmentation between communities, we are ready for the main results of the model. Below, Proposition 1 states that if two communities both have a majority ethnicity and that their non-criminals are pivotal in determining the amount of spending on police services then the community with the larger fragmentation will weakly spend more on police services. 
Proposition 1 Consider two communities $q$ and $q^{\prime}$ in which the former is deemed to have a higher level of fragmentation by either Lemma 1 or Lemma 2 and their respective spending on police services are $\bar{e}$ and $\bar{e}^{\prime}$. If $\alpha>0, q_{1}\left(\frac{f(\bar{e})}{\theta}\right)>0.5$ and $q_{1}\left(\frac{f\left(\bar{e}^{\prime}\right)}{\theta}\right)>0.5$ then $\bar{e} \geq \bar{e}^{\prime}$.

Proof. See Appendix.

The above result formalizes the notion that the differential victimization cost drives the positive relationship between ethnic fragmentation and spending on police services. Note that our requirement that the pivotal voter is a majority non-criminal is a relatively innocuous one, as 3016 of the 3021 counties which we examine have a majority ethnic group. ${ }^{8}$ The next result formalizes that the absence of the differential victimization cost implies no such relationship between ethnic fragmentation and spending on police services.

Corollary 1 If $\alpha=0$ then $\bar{e}$ does not vary with $q$.

Proof. See Appendix

Together, Proposition 1 and Corollary 1 constitute our interpretation of the data which follows. We contend that if we observe a positive relationship between ethnic fragmentation and spending on police services, this provides evidence of the differential disutility of interethnic victimization and hence a larger cost of fear of crime.

\section{Data and Methodology}

In this paper, we are concerned with how ethnic fragmentation affects preferences for police services. Therefore, we use per-capita county level police expenditures as our dependent variable. To empirically address this subject, we take our econometric specification from the demand for public spending literature. We use the median voter model as a framework for aggregating individual voter preferences into a community spending demand function. This function represents the characteristics of the median voter, which often include tax price, income, population, and other variables. We use the functional form for the demand for public spending as established by Bergstrom and Goodman (1972) and Borcherding and Deacon (1972).

The main independent variable is the fragmentation index, which is given in expression (1). Higher values of ethnic fragmentation ${ }^{9}$ mean that the community is more diverse. To bolster our claim that the differential cost of the fear of crime victimization is driving the relationship between ethnic fragmentation and spending on police services, we include other explanatory

\footnotetext{
${ }^{8}$ In 1990, 2898 of the counties had a white majority, 88 had a black majority, 19 had a native majority, 10 had a Latino majority and 4 had an Asian majority.

${ }^{9}$ We focus on ethnic fragmentation rather than racial fragmentation as we wish to separate out Hispanics from the other racial groups. Chiricos et al (2001) found that increases in perceived level of Hispanics increases fear of crime for Whites (though the sample only included Florida).
} 
variables. ${ }^{10}$ These independent variables include standard covariates like median household income, intergovernmental aid, owner-occupied, population density, share of population with a bachelor's degree and crime rate. Finally, we include the relative proportions of ethnic groups. Vigdor (2002) argued that including this variable allows one to estimate the impact of individual groups on spending separately from the community composition. The data is a panel of 3,122 U.S. counties for 1990 and 2000. ${ }^{11}$ The demographic variables are taken from the Census Bureau, which is merged with the financial variables that are also taken from the Census Bureau's Census of Governments. We list the financial variables in 2000 dollars. A summary of the variables is given in the table below.

Table 1. Variable Means Across Panel Years

\begin{tabular}{|l|l|l|}
\hline$(\mathrm{N}=6,244)$ & 1990 & 2000 \\
\hline Police Spending & 73.58 & 117.15 \\
\hline Crime per 100,000 & 0.030 & 0.024 \\
\hline Ethnic Fragmentation & 0.17 & 0.25 \\
\hline Owner-occupied & 0.73 & 0.74 \\
\hline Median Income & $30,911.89$ & $32,626.89$ \\
\hline College & 0.14 & 0.17 \\
\hline Density & 192.6 & 210.9 \\
\hline Federal Aid & 749.97 & $1,285.29$ \\
\hline Black & 0.086 & 0.087 \\
\hline Native & 0.016 & 0.017 \\
\hline Asian & 0.007 & 0.009 \\
\hline Other & 0.018 & 0.012 \\
\hline Hispanic & 0.035 & 0.062 \\
\hline Less than High School & 0.194 & 0.226 \\
\hline Ethnic (prior) & 0.14 & 0.17 \\
\hline
\end{tabular}

Ordinary Least Squares $(O L S)$ estimation could be inappropriate when estimating the impact of local public demand as spending on local public goods depends on a number of factors which end up being right hand side variables. Poterba (1997) states, "Studying local jurisdictions brings a different set of empirical problems, because the demographic composition of a small community cannot be viewed as exogenous, but rather depends on the structure of local public spending." Somewhat more simply, the size of public spending is a factor when people decide to move to a given location. Following the literature, we use the prior Census value of ethnic fragmentation as an instrument.

We expect that the crime rate would affect the demand for police spending. ${ }^{12}$ However,

\footnotetext{
${ }^{10}$ While we would like to obtain data regarding the differences between interethnic and intraethnic crime, such data at the county level is not readily available.

${ }^{11}$ Several counties were lost during the merge of the demographic and financial variables. Also not included are counties in Alaska, Hawaii and the District of Columbia.

${ }^{12}$ We also attempted to look at differences by type of crime, but there is not consistent county level data for all of the United States.
} 
this relationship is not straightforward as there are endogeneity problems. For instance, an increase in crime would likely lead to an increase in police spending. Therefore, we attempt the difficult task of choosing an instrument which is correlated with crime, but not police spending. A glance at the empirical crime literature should prove helpful in this regard. Buonanno (2003) outlines several factors which are potentially correlated with crime including income inequality, the population aged 15-24, share of population with less than a high school education, and the neighborhood poverty rate. Kelly (2000) shows that income inequality is positively correlated with crime. Doyle, Ahmed, and Horn (1999) do not find that inequality is correlated with crime, but they do find that the male youth population has a positive effect on crime. Lochner and Moretti (2004) show that increases in individuals' educational attainment lower crime. We tried several measures including black male youth population, income inequality, and the poverty rate, but decided to use the share of population with less than a high school diploma. ${ }^{13}$

We estimate a panel instrumental variables model using a $G M M$ procedure that is efficient in the presence of heteroskedascity. All variables are in logarithms. County and timespecific fixed effects are included. We test for overidentification using Hansen's J statistic and instrument relevance using the Anderson (1984) canonical correlation test (see Baum et al (2006)). The test statistic was 17.09, therefore the equation is not underidentified. Table 2 gives the results of the estimation.

Table 2. Panel Instrumental Variable Estimation Results ${ }^{14}$

\begin{tabular}{|c|c|}
\hline & Police Spending \\
\hline Ethnic Fragmentation & $0.596^{* *} ;(0.27)$ \\
\hline Crime per 100,000 & $-0.581^{* * *} ;(0.20)$ \\
\hline Owner-Occupied & $-0.918 ;(0.91)$ \\
\hline Median Income & $-0.020 ;(0.01)$ \\
\hline College & $0.334 ;(0.29)$ \\
\hline Population Density & $-0.575^{* * *} ;(0.23)$ \\
\hline Federal Aid & $0.343^{* *} ;(0.14)$ \\
\hline Share Black & $-0.028 ;(0.03)$ \\
\hline Share Native & $0.119^{* *} ;(0.06)$ \\
\hline Share Asian & $-0.001 . ;(0.03)$ \\
\hline Share Other & $0.048^{*} ;(0.03)$ \\
\hline Share Hispanic & $0.032 ;(0.06)$ \\
\hline
\end{tabular}

\footnotetext{
${ }^{13}$ In the estimation, the Shea Partial $R 2$ for ethnic was 0.0428 with an $F$-statistic of 29.05. The Shea Partial $R 2$ for crime was 0.0056 with an $F$-statistic of 12.78 . The $F$ statistics for the other instruments were below 10 and therefore considered weak (see Staiger and Stock (1997)).

${ }^{14}$ While the null hypothesis of underidentification was rejected, there may still be a problem with weak instruments. Thus, we also use the Cragg-Donald $F$-statistics, which showed that the instruments were not weakly correlated with the endogenous variables.
} 
The most obvious point from Table 2 is that the ethnic fragmentation index has a positive and significant coefficient. This confirms our hypothesis that increases in ethnic fragmentation lead to increases in police spending. Again, we interpret this empirical result as supporting the contention that people have a differential cost of fear of crime victimization when the perpetrator is a different ethnicity. Another item of note is that the coefficient on crime is negative. Of course, this indicates a negative relationship between crime and spending on police services which is not surprising since this study was conducted at a time in which crime was decreasing and spending was increasing.

Finally, the reader might wish to know whether the results are driven by the higher or lower income counties. We address this concern through Table 3.

Table 3 Panel Instrumental Variable Estimation by Income Percentile ${ }^{15}$

\begin{tabular}{|l|l|l|l|l|}
\hline Percentile & $25 \%$ & $50 \%$ & $75 \%$ & $99 \%$ \\
\hline Fragmentation & $0.037 ;(0.029)$ & $0.128^{*} ;(0.077)$ & $0.226^{* *} ;(0.091)$ & $\left.0.072^{* * *} ; 0.028\right)$ \\
\hline Crime Rate & $-0.003 ;(0.009)$ & $-0.012 ;(0.010)$ & $-0.104^{* * *} ;(0.039)$ & $-0.016^{* *} ;(0.007)$ \\
\hline N & 1558 & 1558 & 1558 & 1558 \\
\hline
\end{tabular}

In Table 3 we separated the sample into income percentiles based on 1990 median incomes: The first column represents the counties with incomes in the lowest $25 \%$. The next column shows the counties with incomes between $25 \%$ and the median. The third column shows the counties with incomes above the median and below $75 \%$. The final column shows the counties with the highest percentile. Table 3 shows that fragmentation is positively related to police spending in counties with incomes above the median while the crime rate is negatively related to these same counties. Thus, we cannot say that certain income groups drive the results of Table 2 because the results are significant for at least half the sample.

\section{Conclusion}

We have presented empirical results which suggest that ethnic fragmentation is positively related to spending on police services. We have also presented a model which we have used to interpret these empirical results. We view the work to this point as supporting the claim that people have a larger disutility of crime victimization when the perpetrator is a different ethnicity.

Future research on the matter will examine the potential spillover effects of police spending using spatial analysis techniques. Finally, there are, of course, other possible explanations for the results presented in this paper. For instance, it could be the case that more fragmented

\footnotetext{
${ }^{15}$ In separating the sample, we find that we cannot run the same models for each group. For the sample above the median and below the $75 \%$, we do run the panel IV regression instrumenting for Fragmentation and Crime Rate. For the sample above the $25 \%$ and below the median, we run the panel IV regression but only instrument for Fragmentation. For the other samples, we run the standard panel regression.
} 
communities have a larger share of outgroup crime. It also could be the case that outgroup crime is more brutal than ingroup crime. In these cases, the empirical relationship described in this paper might not have resulted from a differential disutility of crime victimization. Addressing these matters will constitute future work. 


\section{Appendix}

Proof of Lemma 1: First note that $q_{\beta}^{\prime}>q_{\alpha}^{\prime}$ implies $q_{b}>q_{a}$.

$$
\begin{aligned}
q_{\beta}^{\prime} & >q_{\alpha}^{\prime} \\
q_{b}-A & >q_{a}+A
\end{aligned}
$$

We write the fragmentation of $q$ as:

$$
\phi(q)=1-q_{1}^{2}-q_{2}^{2}-\ldots-q_{n}^{2}
$$

and the fragmentation of $q^{\prime}$ as:

$$
\phi\left(q^{\prime}\right)=1-q_{1}^{\prime 2}-q_{2}^{\prime 2}-\ldots-q_{n}^{\prime 2}
$$

Since the communities have $N-2$ groups of equal size (every group with the exception of $q_{\beta}^{\prime}, q_{\alpha}^{\prime}$ and $\left.q_{b}, q_{a}\right)$ we can write

$$
\phi(q)-\phi\left(q^{\prime}\right)=\left(q_{\alpha}^{\prime 2}-q_{a}^{2}\right)+\left(q_{\beta}^{\prime 2}-q_{b}^{2}\right)
$$

where only groups $q_{a}$ and $q_{b}$ are not of equal size with $q_{\alpha}^{\prime}$ and $q_{\beta}^{\prime}$. And so

$$
\begin{aligned}
\phi(q)-\phi\left(q^{\prime}\right) & =2 A q_{\alpha}^{\prime}-A^{2}-2 A q_{\beta}^{\prime}-A^{2} \\
& =-2 A^{2}-2 A\left(q_{\alpha}^{\prime}+q_{\beta}^{\prime}\right)<0
\end{aligned}
$$

and the lemma is proved

Proof of Lemma 2: Consider two communities $q$ and $q^{\prime}$ which differ only in that the former group $k$ is the sum of groups $\kappa$ and $\delta$ in the latter. In particular assume:

$$
\begin{gathered}
q_{\kappa}^{\prime}=q_{k}-x>0 \\
q_{\delta}^{\prime}=x>0
\end{gathered}
$$

Therefore:

$$
\begin{aligned}
\phi(q)-\phi\left(q^{\prime}\right) & =q_{\kappa}^{\prime 2}+q_{\delta}^{\prime 2}-q_{k}^{2} \\
& =2 x\left(x-q_{k}\right)<0
\end{aligned}
$$

and so the lemma is proved.

Proof of Proposition 1: Since we are restricting attention to comminutes with $q_{1}\left(\frac{f(\bar{e})}{\theta}\right)>$ 0.5 the median voter will be a non-criminal from the majority ethnicity. A person will commit a crime if their utility from crime $(x)$ is greater than $c$. We have also assumed that the propensity to commit a crime is a uniform distribution on $[0, \theta]$. Therefore the probability 
that a person will commit a crime is:

$$
p(e)=\frac{\theta-f(e)}{\theta}
$$

In the first period we can write the utility of a person who will not commit a crime in the second period as:

$$
U_{i, N C}=u\left(w-e_{i}\right)-\left(\frac{\theta-f\left(e_{i}\right)}{\theta}\right)\left(1+\left(1-q_{j}\right) \alpha\right)
$$

and the utility of a person who will commit a crime in the second period as:

$$
U_{i, C}=u\left(w-e_{i}\right)-\left(\frac{\theta-f\left(e_{i}\right)}{\theta}\right)\left(1+\left(1-q_{j}\right) \alpha\right)+x-f(\bar{e})
$$

We write the most preferred choice of per capita police spending of agent $i$ as $e_{i}^{*}$. For the person who will not commit a crime the first order condition is

$$
u^{\prime}\left(w-e_{i}^{*}\right)=f^{\prime}\left(e_{i}^{*}\right)\left(\frac{1}{\theta}\left(1+\left(1-q_{j}\right) \alpha\right)\right)
$$

and for those who will commit a crime is:

$$
u^{\prime}\left(w-e_{i}^{*}\right)=f^{\prime}\left(e_{i}^{*}\right)\left(\frac{1}{\theta}\left(1+\left(1-q_{j}\right) \alpha\right)-1\right)
$$

Note that expression (5) does not hold if $\frac{1}{\theta}\left(1+\left(1-q_{j}\right) \alpha\right)-1<0$. If this is the case it will be that $e_{i}^{*}=0$.

Recall that the functions $u($.$) and f($.$) are differentiable, increasing and concave. Ex-$ pression (2) implies that the non-criminals which are ethnicity $q_{1}$ will have interior (strictly between 0 and $w$ ) optimal preference regarding spending on police services. Therefore by expression (4) the value of $e_{i}^{*}$ is increasing as the share of the outgroup population. Additionally, there will be a unique $e_{i}^{*}$ which satisfies expression (4).

Standard median voter arguments imply that the preferences of the median voter will be the winning policy. Therefore the preference for spending on police services of the noncriminals of the majority group will prevail: $e_{i}^{*}=\bar{e}$.

Consider the case where we invoke Lemma 1 . Suppose that community $q$ contains groups $q_{a}$ and $q_{b}$ and that community $q^{\prime}$ contains groups $q_{\alpha}$ and $q_{\beta}$. Then by Lemma 1 it must be that $\phi(q)<\phi\left(q^{\prime}\right)$. If $q_{\beta}^{\prime}\left(\frac{f(\bar{e})}{\theta}\right) \geq 0.5$ then $\bar{e}<\bar{e}^{\prime}$. If $q_{b}\left(\frac{f(\bar{e})}{\theta}\right) \geq 0.5>q_{\beta}^{\prime}\left(\frac{f(\bar{e})}{\theta}\right)$ then the Proposition does not apply as community $q^{\prime}$ would not have a group larger than 0.5. If $0.5>\left(\frac{f(\bar{e})}{\theta}\right) q_{b}$ then the preferences of the majority are not affected and therefore $\bar{e}=\bar{e}^{\prime}$.

Consider the case where we invoke Lemma 2. Suppose that community $q$ and $q^{\prime}$ differ only by one group $q_{k}$ in $q$ which is equal to the union of groups $q_{\kappa}$ and $q_{n+1}$ in $q^{\prime}$. Then by Lemma 2 it must be that $\phi(q)<\phi\left(q^{\prime}\right)$. If the split group is $q_{1}$ then $\bar{e}<\bar{e}^{\prime}$. If the split group 
is not $q_{1}$ then the preferences of the majority are not affected and therefore $\bar{e}=\bar{e}^{\prime}$. As we have covered both cases, we have proved the Proposition.

Proof of Corollary 1: When $\alpha=0$ the right side of expressions (4) and (5) do not vary with $1-q_{j}$ and so $\bar{e}$ does not vary with fragmentation. 


\section{References}

Alesina, Alberto, Baqir, Reza and Easterly, William (1999): "Public Goods and Ethnic Divisions," Quarterly Journal of Economics, 114: 1243-84.

Alesina, Alberto, Devleeschauwer, Arnaud, Easterly, William and Kurlat, Sergio (2003): "Fractionalization," Journal of Economic Growth, 8(2): 155-195.

Alesina, Alberto and La Ferrara, Eliana (2005): "Ethnic Diversity and Economic Performance," Journal of Economic Literature, 43: 721-761.

Bandyopadhyay, Siddhartha and Chatterjee, Kalyan (2006): "Crime as a Local Public Bad, Neighborhood Observation and Reporting," unpublished University of Birmingham and Pennsylvania State University.

Barkan, Steven E., and Steven F. Cohn. (2005) "Why Whites Favor Spending More Money to Fight Crime: The Role of Racial Prejudice" Social Problems, 52(2): 300-314.

Baum, C.F., Schaffer, M.E., Stillman, S., (2006). ivreg2: Stata module for extended instrumental variables/2SLS, GMM and AC/HAC, LIML and k-class regression.

http://ideas.repec.org/c/boc/bocode/s425401.html.

Becker, Gary (1968): "Crime and Punishment: An Economic Approach," Journal of Political Economy, 76: 169-217.

Bergstrom, T. and R. Goodman, (1973). "Private Demands for Public Goods," American Economic Review 63, 280-96.

Bergstrom, T., D. Rubinfeld, and P. Shapiro, (1982). "Micro-Based Estimates of Demand Functions for Local School Expenditures," Econometrica 50(5), 1183-1206.

Borcherding, T. and R. Deacon, (1972). "The Demand for the Services of Non-Federal Governments," American Economic Review 62, 891-901.

Buonanno, P. 2003. "The Socioeconomic Determinants of Crime: A Review of the Literature" Working Paper.

Burdett, Kenneth, Lagos, Ricardo and Wright, Randall (2003): "Crime, Inequality and Unemployment," American Economic Review, 93(5): 1764-1777.

Bursik, Robert, and Harold Grasmick. (1993) Neighborhoods and Crime: The Dimensions of Effective Community Control (New York: Lexington Books)

Chiricos, Ted, McEntire, Ranee, and Marc Gertz (2001) "Perceived Racial and Ethnic Composition of Neighborhood and Perceived Risk of Crime" Social Problems, 48(3): 322-340. 
Criminal Victimization and Perceptions of Community Safety in 12 Cities, (1998), BJS Report, NCJ 173940, May 1999.

Doyle, J., E. Ahmed, and R. Horn, (1999). "The Effects of Labor Markets and Income Inequality on Crime: Evidence from Panel Data" Southern Economic Journal 65(4): 717-738

Esteban, Joan and Ray, Debraj (1994): "On the Measurement of Polarization," Econometrica, 62(4): 819-851.

Fender, John (1999): "A General Equilibrium Model of Crime and Punishment," Journal of Economic Behavior and Organization, 39: 437-453.

Hero, R. and C. Tolbert, (1996). "A Racial/Ethnic Diversity Interpretation of Politics and Policy in the State of the U.S." American Journal of Political Science 40(3), 851-871

Kelly, M. (2000). "Inequality and Crime" Review of Economics and Statistics 82(4): 530539

Locher, L. and E. Moretti. (2004). "The Effect of Education on Crime: Evidence from Prison Inmates, Arrests, and Self-Reports" American Economic Review 94(1): 155-189

Luttmer, Erzo (2001): "Group Loyalty and the Taste for Redistribution," Journal of Political Economy, 109(3): 500-528.

Machin, Stephen and Marie, Olivier (2005): "Crime and Police Resources: The Street Crime Initiative," unpublished University College London, London School of Economics and Centre for Economic Performance.

Marlow, Michael L., and Alden F. Shiers. (1999) "Do Law-Enforcement Expenditures Crowd Out Public Education Expenditures?" Applied Economics, 31(2): 255-266

Moore, Simon (2006): "The Value of Reducing Fear: an Analysis Using the European Social Survey," Applied Economics, 38: 115-117.

Moore, Simon and Shepherd, Jonathan (2006): "The Cost of Fear: Shadow Pricing the Intangible Costs of Crime," Applied Economics, 38: 293-300.

Moore, Simon and Shepherd, Jonathan (2007): "The Elements and Prevalence of Fear," British Journal of Criminology, 47: 154-162.

Nielsen, F. and A. S. Alderson. (1997). "The Kuznets Curve and the Great U-Turn: Income Inequality in U.S. Counties, 1970 to 1990." American Sociological Review 62:12-33.

Perrson, Mats and Claes-Henric, Siven (2006): "Incentive and Incarceration Effects in a General Equilibrium Model of Crime," Journal of Economic Behavior and Origination, 59: 214-229. 
Pettinico, George (1994) "Crime nad Punishment: America Changes Its Mind." The Public Perspective: A Roper Center Review of Public Opinion and Polling Vol. 5:29- 2.

Poterba, J., (1997). "Demographic Structure and the Political Economy of Public Expenditure," Journal of Policy Analysis \& Management 16, 48-66.

Quillian, Lincoln, and Devah Pager. (2001) "Black Neighbors, Higher Crime? The Role of Racial Stereotypes in Evaluations of Neighborhood Crime" American Journal of Sociology, 107(3): 717-767.

Staiger, Douglas, and James H. Stock. (1997) "Instrumental Variables Regression With Weak Instruments" Econometrica, 65(3): 557-586.

Statistical Abstract of the United States, various years, Bureau of the Census

Vigdor, J., (2002). "Interpreting Ethnic Fragmentation Effects," Economics Letters 75, $271-276$. 